Mason, J. (1953). J. gen. Microbiol. 8, 263-264.

\title{
Isolation of Anaerobic Bacteria by a Modified Shake Method
}

\author{
By J. H. MASON \\ South African Institute for Medical Research, Johannesburg
}

SUMMARY : Isolated colonies of anaerobic bacteria can be obtained in a layer of agar enclosed between a watch-glass and a glass plate. They can be examined and removed without difficulty.

The excuse for introducing yet another way of isolating anaerobic bacteria is that it possesses some advantages over existing methods and should prove of value in small laboratories not provided with special apparatus. In deep nutrient agar, discrete, well-developed colonies can be obtained with regularity but their examination and removal can be difficult. This can be overcome by cultivating the microbes in a layer of agar contained between two plates of glass clamped on a U-shaped metal support (Mason, 1930). Unfortunately, because the edges of the agar are then exposed to air, contamination and shrinkage of the medium is the rule with this method. These disadvantages are removed in the method to be described.

The apparatus required consists of watch-glasses of between 5 and $10 \mathrm{ml}$. capacity, glass plates about $10 \mathrm{~cm}$. square, nutrient agar, serum, drawn-out pipettes, a platinum loop, and paraffin wax. The borders of the watch-glasses on the concave side are ground flat so that they will adhere firmly to the plates. The glasses and plates are wrapped in paper and sterilized by moist or dry heat. Nutrient agar in tubes is melted, cooled to $50^{\circ}$ and serum added to give a $10 \%(\mathrm{v} / \mathrm{v})$ concentration. The microbes under test are added and thoroughly dispersed. The inoculated medium is then poured into the watch-glass held under, and projecting slightly beyond the edge of, the horizontal glass plate. As the watch-glass fills, it is slowly slipped right on to the plate, but an air bubble is allowed to take the place of the last drop of agar so as to avoid overflow. The plate is placed on edge to allow the agar to set with the bubble at the circumference of the watch-glass. After ringing the watch-glass with wax, the apparatus is incubated at $37^{\circ}$.

The serum agar must be clear, firm and capable of supporting the growth of the anaerobe under examination. Fermentable sugar should not be added, in order to minimize gas formation; in fact, it may be necessary to remove some of the carbohydrates from the mother broth by fermentation methods if gas formation is troublesome. Colonies, visible to the eye, develop within $24 \mathrm{hr}$. The wax is then removed and the watch-glass levered off with a sterile thin-bladed knife. Then, under a low power microscope or under a lens, the chosen colony is sucked into a pipette and expelled into broth.

Excellent results have been obtained with Clostridium tetani, Cl. chauvoei, Cl. septicum and $\mathrm{Cl}$. oedematiens. $\mathrm{Cl}$. chawvoei has been isolated from a mixture 
of $\mathrm{Cl}$. chauvoei and $\mathrm{Cl}$. septicum and from a mixture of $\mathrm{Cl}$. chauvoei and $\mathrm{Cl}$. oedematiens. It will be appreciated by those accustomed to the isolation of anaerobes that this method is but a refinement of an existing technique and is not $\dot{a}$ solution of all the difficulties inherent in this type of work. To expect to isolate $\mathrm{Cl}$. chauvoei from a culture grossly contaminated with $\mathrm{Cl}$. sporogenes, Bacterium coli and a staphylococcus is asking too much. All means at the disposal of the technician, such as differential heating, cultivation in selective media and passage through"small animals, should be used to bring to a minimum the number of concomitant bacteria before colony isolation methods are applied.

\section{REFERENCE}

Mason, J. H. (1930). The cultivation of anaerobic organisms. Vet. J. 86, 474.

(Received 18 August 1952) 